\title{
Reduction of inter-observer differences in the delineation of the target in spinal metastases SBRT using an automatic contouring dedicated system
}

Niccolò Giaj-Levra1* ${ }^{1 *}$, Vanessa Figlia ${ }^{1}$, Francesco Cuccia ${ }^{1}$, Rosario Mazzola ${ }^{1}$, Luca Nicosia ${ }^{1}$, Francesco Ricchetti ${ }^{1}$, Michele Rigo', Giorgio Attinà', Claudio Vitale', Gianluisa Sicignano', Antonio De Simone', Stefania Naccarato', Ruggero Ruggieri ${ }^{1}$ and Filippo Alongi, ${ }^{1,2}$

\begin{abstract}
Background: Approximately one third of cancer patients will develop spinal metastases, that can be associated with back pain, neurological symptoms and deterioration in performance status. Stereotactic radiosurgery (SRS) and stereotactic body radiotherapy (SBRT) have been offered in clinical practice mainly for the management of oligometastatic and oligoprogressive patients, allowing the prescription of high total dose delivered in one or few sessions to small target volumes, minimizing the dose exposure of normal tissues. Due to the high delivered doses and the proximity of critical organs at risk (OAR) such as the spinal cord, the correct definition of the treatment volume becomes even more important in SBRT treatment, thus making it necessary to standardize the method of target definition and contouring, through the adoption of specific guidelines and specific automatic contouring tools. An automatic target contouring system for spine SBRT is useful to reduce inter-observer differences in target definition. In this study, an automatic contouring tool was evaluated.
\end{abstract}

Methods: Simulation CT scans and MRI data of 20 patients with spinal metastases were evaluated. To evaluate the advantage of the automatic target contouring tool (Elements SmartBrush Spine), which uses the identification of different densities within the target vertebra, we evaluated the agreement of the contours of 20 spinal target (2 cervical, 9 dorsal and 9 lumbar column), outlined by three independent observers using the automatic tool compared to the contours obtained manually, and measured by DICE similarity coefficient.

Results: The agreement of GTV contours outlined by independent operators was superior with the use of the automatic contour tool compared to manually outlined contours (mean DICE coefficient 0.75 vs $0.57, p=0.048$ ).

Conclusions: The dedicated contouring tool allows greater precision and reduction of inter-observer differences in the delineation of the target in SBRT spines. Thus, the evaluated system could be useful in the setting of spinal SBRT to reduce uncertainties of contouring increasing the level of precision on target delivered doses.

Keywords: Radiotherapy, Stereotactic, Software, Spine, Metastases

*Correspondence: niccolo.giajlevra@sacrocuore.it

${ }^{1}$ Advanced Radiation Oncology Department, Sacro Cuore Don

Calabria Hospital, IRCCS Ospedale Sacro Cuore Don Calabria, Via Don A.Sempreboni 5, 37124 Negrar Di Valpolicella, VR, Italy

Full list of author information is available at the end of the article

\section{Introduction}

Local back pain and neurological symptoms are the most common clinical disease presentations in spinal metastases [1]. Traditionally, surgical decompression original author(s) and the source, provide a link to the Creative Commons licence, and indicate if changes were made. The images or other third party material in this article are included in the article's Creative Commons licence, unless indicated otherwise in a credit line to the material. If material is not included in the article's Creative Commons licence and your intended use is not permitted by statutory regulation or exceeds the permitted use, you will need to obtain permission directly from the copyright holder. To view a copy of this licence, visit http://creativecommons.org/licenses/by/4.0/. The Creative Commons Public Domain Dedication waiver (http://creativecommons.org/publicdomain/zero/1.0/) applies to the data made available in this article, unless otherwise stated in a credit line to the data. 
and palliative radiotherapy have been recognized as the main treatment options for these patients. Nevertheless, both oncological approaches were associated with a limited local control probability [2] and pain relief [3]. Nonetheless, radiation therapy is still considered one of the important therapeutic options in the management of spinal metastases. In fact, in the last decades, significant non-invasive technological improvements have been observed in modern radiotherapy. Accurate radiological staging, as magnetic resonance imaging (MRI) and metabolic images (PET-CT), allows to detect any metastatic disease presentation earlier. Moreover, in the oligometastatic and oligoprogressive patients, it is progressively becoming current clinical practice to prescribe local ablative radiation treatments (SBRT) [4-6]. The combination of both strategies has the purpose to prescribe earlier ablative treatments, prevent local symptoms and postpone the prescription of new systemic treatments. In fact, SBRT allows prescribing in a limited number of fractions, high dose irradiation to small target volumes, and minimizing the dose exposure to organ at risks (OARs) [7-9]. This favorable characteristic is crucial in spinal metastases, in which an appropriate target volume definition is mandatory to avoid tumor missing, without compromising tumor coverage. For this reason, in the radiation oncology community, a standardized method in target definition is advocated, through specific guidelines and the development of contouring tools $[10,11]$. As previously reported [12], a dedicated software has been developed for patients eligible to SBRT in spinal metastases (Elements Spine SRS ${ }^{\circledR}$, Brainlab ${ }^{\mathrm{TM}}$ Germany). The preliminary results reported an excellent local control probability and a good toxicity profile. Despite this, the possibility to use an automatic target contouring tool (Elements SmartBrush Spine; hereby referred to as SmartBrush) could potentially support radiation oncologists to uniform the outline process. In fact, the principal advantage of the SmartBrush tool is represented by the identification of different density grey levels, which can decrease the inter-observer differences in target definition. The aim of the present study is to assess the SmartBrush impact in patients with spinal metastases, eligible for SBRT.

\section{Materials and methods}

\section{Patients and treatment}

In the current study, we analyzed the impact of the SmartBrush software (Elements SmartBrush Spine, Brainlab $^{\mathrm{TM}}$ Germany) in patients with spinal metastases. Specifically, 20 spinal lesions eligible for SBRT treatments were included in the study. In all cases, 20 target volumes were equally visible and delineable both in CT scans (as osteolytic or thickening areas) and in MRI scans. All the procedures have been described in a previous publication [12]. Briefly, patient simulation was performed by acquiring a $1 \mathrm{~mm}$-slice thickness $\mathrm{CT}$ scan with the aid of a head or abdomen thermoplastic mask, depending on the treatment site. The field of view was adjusted to cover the whole body along the entire tract of interest of the column.

For MRI scans, a T2-weighted sequence was rigidly registered with the simulation CT scan for a refined definition of healthy structures such as spinal cord, sacral plexus or cauda equina. The organs at risk (OARs), depending on tumor site, were automatically delineated by the software based on an anatomical atlas.

For baseline treatment, the gross tumor volume (GTV) was defined as the macroscopic contrast-enhancing lesion detected on diagnostic imaging; Smartbrush software allows an easier recognition of the affected region with a direct adjustment for CTV refined definition. No GTV manual refinement is performed. The clinical target volume (CTV) was automatically generated by the software according to international guidelines and automatically labeled to avoid vertebral crossing [11]. Afterwards, the CTV was cropped where adjacent to the spinal canal. The planning target volume (PTV) was obtained by adding an isotropic margin of $2 \mathrm{~mm}$ to the CTV, avoiding any potential overlap with the spinal canal. Prescribed dose and fractionation were chosen based on the tumor volume, previous spinal radiation treatment and OAR tolerance limits. Corticosteroid therapy was prescribed only if patient reported pain or any neurological symptoms.

To evaluate the impact of the automatic target contouring tool (SmartBrush), which uses the identification of different densities within the target vertebra, we evaluated the agreement of the contours of GTV of 20 spinal targets ( 2 cervical, 9 dorsal and 9 lumbar column) outlined by three independent observers experienced in spine SBRT treatments, using the automatic tool compared to the contours obtained manually and measured by DICE similarity coefficient.

Given the different contouring by independent observers as A and B, the Dice coefficient is defined as:

$$
C_{\text {dic }}=\frac{2|A \cap B|}{|A|+|B|} .
$$

The Dice coefficient represents the ratio of overlapped region between different contoured target volumes $\left(0 \leq \mathrm{C}_{\mathrm{dic}} \leq 1\right)$.

The maximum value of $C_{\mathrm{dic}}$ is 1 when the volumes are identical, and the minimum value is 0 when the contours are fully totally dissimilar. This index has the properties of a metric system and it has been extensively used to quantify contouring agreement among observers. We did not consider it relevant to evaluate the variations of the 
CTV as they are dependent, according to the guidelines of International Spine Radiosurgery Consortium [11], more on the localization of the GTV within the vertebra, than on its extension and therefore scarcely modifiable by small variations of the GTV volume.

\section{Statistical analysis}

To evaluate the performance difference, a Student's t-test for two independent samples was used by assuming a normal distribution for the obtained metric values. A significance level of $5 \%$ was considered to show a statistically significant difference between the performances of two contouring tool (SmartBrush versus manual contouring).

\section{Results}

Data from 20 patients treated for spine metastases were extracted for the purpose of the present analysis. More specifically, 2 were cervical targets, 9 thoracic and 9 were located in the lumbar spine. A median prescription dose of 24 Gy was delivered in 3 fractions using imageguided volumetric modulated arc therapy by means of a TrueBeam linear accelerator (Varian Medical System PA, California). A simultaneous integrated boost to the GTV was delivered for a median prescription dose of $27 \mathrm{~Gy}$ in 3 fractions.

Median GTV volume was $1.44 \mathrm{cc}$ (range, 0.35-18.8), median CTV volume was $22.1 \mathrm{cc}$ (range, 13.6-28.9). Examples of target volume delineation are displayed in Fig. 1.

The agreement of GTV contours outlined by three independent operators was statistically superior $(p=0.048)$ with the use of the automatic contour tool (SmartBrush), that registered a mean DICE coefficient of 0.75 (with $95 \%$ confidence interval of 0.71-0.79) compared to manually outlined contours, that registered a mean DICE coefficient of 0.57 (95\% confidence interval of 0.53-0.62), Fig. 2.

\section{Discussion}

Radiation therapy represents a consolidate highly effective local approach for patients with spinal metastases, due to its potential cytoreductive effects on local disease to prevent possible neurological deterioration and its ability to relieve pain. In recent decades, spinal SBRT is emerging as an innovative and effective technique in the local control of spinal metastases in oligometastatic patients, for its capacity of delivering high radiation doses, potentially improving local control rates, as reported in patients with brain and extracranial metastases and early-stage non-small cell lung cancer $[13,14]$.

In recent years, it has been shown that the use of SBRT in spinal metastases was associated with a faster and improved pain response compared to conventional fractionated palliative radiotherapy, as demonstrated by a recent randomized phase II trial [15]. In different prospective trials and literature review, SBRT proves to be an effective and safe treatment option for spinal metastases, with a limited risk of complications, including vertebral compression fracture, flair pain and symptomatic myelopathy $[16,17]$, as also shown in our previous experience [12]. The results of a randomized phase II/III study have just been presented at ASTRO's Annual Meeting, comparing 24 Gy in 2 stereotactic body radiotherapy (SBRT) fractions versus 20 Gy in 5 conventional palliative radiotherapy (CRT) fractions for patients with painful spinal metastases, confirming the advantage of stereotactic treatment of spinal metastases [18].

For a spinal SBRT approach, even before the accurate administration of the high-dose treatment, allowed by the use of Image-Guided Radiotherapy systems, the correct definition of the target is mandatory for the identification of vertebral lesions and delineation of the
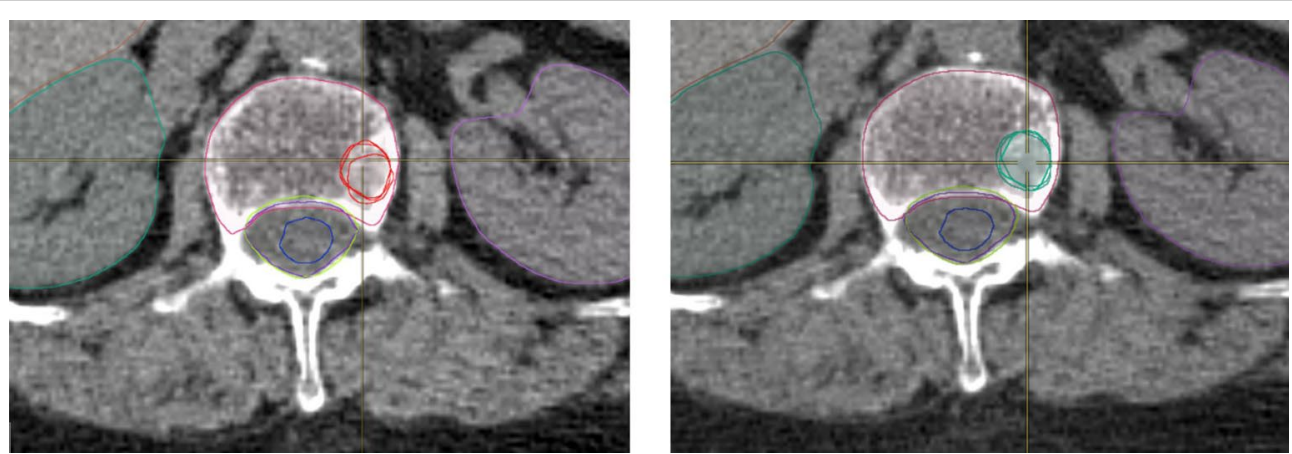

Fig. 1 Axial images examples of GTV delineation by manually method and Smart Brush Tool. Red: Manual contouring. Green: Smart Brush contouring 


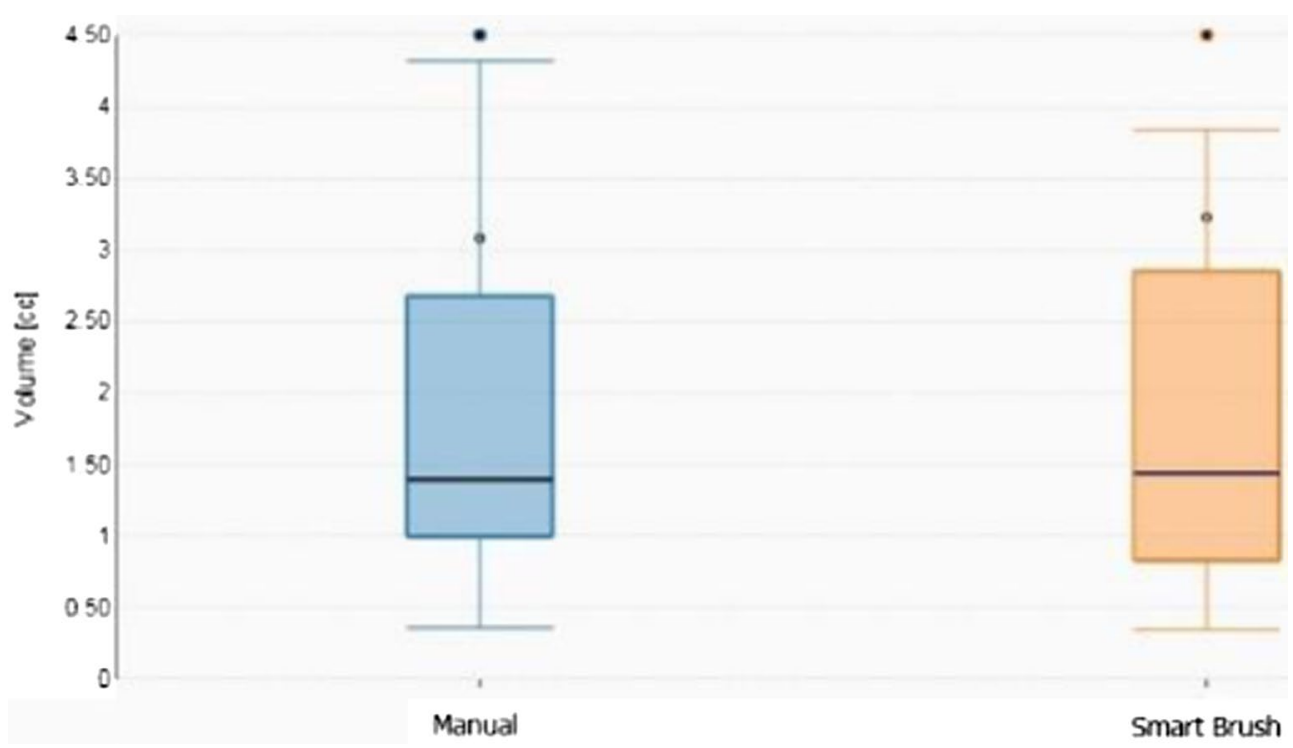

Fig. 2 Boxplot of contour volumes per modality. Turquoise: Manual contouring. Orange: SmartBrush contouring

organs risk present in the treatment field, allowed by the use of multimodal imaging.

In addition of this, the correct definition of the treatment volume becomes even more important in SBRT treatments, due to the high doses that are delivered and the proximity of critical OARs such as the spinal cord, thus making it necessary to standardize the method of target definition and contouring, through the adoption of specific guidelines and specific automatic contouring tools $[10,11]$.

The present study examines a specific contouring tool (SmartBrush) of a dedicated software (Elements ${ }^{\circledR}$, Brainlab $^{\text {TM }}$ Germany) for spinal metastases SBRT. We evaluated the accuracy of this novel specific contouring tool -SmartBrush- applied to retrospective simulation $\mathrm{CT}$ clinically acquired in 20 patients treated with Spine SBRT.

To evaluate the advantage of using an automatic contouring tool (SmartBrush) based on the recognition of areas of different density within the target vertebra, we evaluated the concordance of the contours obtained by three independent observers with and without the use of the SmartBrush tool.

The results showed a statistically greater agreement in the use of the contouring tool analyzed, compared to the manual delineation of the contours, allowing for greater homogeneity in the definition of the target.

This last aspect is more relevant in the accurate definition of the GTV volumes, especially in view of the possibility of performing treatments with simultaneous integrated boost on the lesion evident in PET or MRI, within the vertebral target, to potentially increase local disease control.

To date, few experiences in the literature report on the use of softwares for automatic segmentation of the target in radiotherapy. Hearn et al. have recently published the results of a comparison study between manual segmentation and semi-automated delineation of prostate GTV based on quantitative thresholding of intraprostatic apparent diffusion coefficient (ADC) and PET standardized uptake values (SUV), recording a significantly higher inter-observer agreement with the use of PET compared to MRI-based semiautomatic segmentation [19].

Autosegmentation tools are an attractive option for clinicians, since they are supposed to facilitate everyday clinical practice, by reducing inter-observer variability and potentially reducing contouring time. Nonetheless, the role of the physician still remains irreplaceable. This is also confirmed by Meillan et al. [20] in a comparison study between two different automated segmentation softwares (iPlan and Smart Segmentation) applied for hypofractionated radiotherapy for intracranial lesions. The authors observed a substantial equivalency of both softwares, nevertheless highlighting the need of manual editing to perform the best tailored contouring.

A recent review by Francolini et al. [21] collected the literature experiences reporting preliminary studies of artificial intelligence applied to all phases of radiation treatment planning. Particularly in the segmentation process, the authors reported the use of Dice Similarity Coefficient as the most frequently used tool to test the reliability of several auto-segmentation softwares. 
Despite most of the studies favorably report artificial intelligence systems for automatic contouring for both targets and OARs, some authors also raise concerns due to the need to manually revise and edit automatically generated contours [22].

Further steps forward are awaited from the implementation of deep learning frameworks and artificial intelligence in daily clinical activity, for which some preliminary experiences have been recently published [23-25], supporting the introduction of this technological aids for refining the accuracy in target and OAR identification.

Several advantages might be provided by the introduction of artificial intelligence systems, as machine-learning based networks are supposed to ease the radiation treatment planning procedure in all its phases. The contouring process might be improved both in terms of time-consumption issues and inter-observer variability, as already reported [26].

This study has some limitations; first of all, the small sample size may affect the statistical power of our analysis. Nonetheless, we included three different physicians to better estimate the potential inter-observer variations: the main aim of the present study was to assess the impact of Smartbrush software compared to manual contouring in order to reduce inter-observer variability, $\mathrm{A}$ further analysis with a larger sample, other metrics tools, and the assessment of time consumption issues is currently ongoing at our Department.

Moreover, in the specific setting of spinal metastases SBRT, to the best of our knowledge, the use of automated software for treatment planning and target contouring was previously investigated only in our preliminary institutional experience [12], supporting the use of Elements as a safe and effective tool for the clinician.

Long term follow-up data are warranted to further assess the favorable impact of this technology from a clinical perspective in terms of both toxicity and clinical outcomes.

\section{Conclusions}

The Elements ${ }^{\circledR}$ Spine SRS dedicated software for linacbased spinal SBRT treatment is a useful approach for patients with spinal metastases, improved by a dedicated automatic contouring tool (SmartBrush) that allows greater precision and reduction of inter-observer differences in the delineation of the target in SBRT spines.

\section{Acknowledgements}

Not applicable.

\section{Authors' contributions}

$N G L, V F, F C$ and FA wrote of the manuscript, tables and organized the study. RR, GS, ADS, SN planned patients. VF, FC performed statistical analysis. All authors read and approved the final manuscript.
Funding

Not applicable.

\section{Availability of data and materials}

The patient information may be shared under'IRCCS Sacro cuore - Don Calabria' hospital IRB approval of amendment on a case by case base. The Element ${ }^{\mathrm{TM}}$ planning package is proprietary (BrainLab AG, Munich, Germany) due to patent protection.

\section{Declarations}

Ethics approval and consent to participate

All patients signed a informed consent for the treatment.

Consent for publication

Not applicable.

Competing interests

The authors declare that they have no competing interests.

\section{Author details}

${ }^{1}$ Advanced Radiation Oncology Department, Sacro Cuore Don Calabria Hospital, IRCCS Ospedale Sacro Cuore Don Calabria, Via Don A.Sempreboni 5, 37124 Negrar Di Valpolicella, VR, Italy. ${ }^{2}$ University of Brescia, Brescia, Italy.

Received: 5 August 2021 Accepted: 29 September 2021

Published online: 09 October 2021

\section{References}

1. Wong DA, Fornasier VL, MacNab I. Spinal metastases: the obvious, the occult, and the impostors. Spine. 1990;15:1-4. https://doi.org/10.1097/ 00007632-199001000-00001.

2. Sakaura H, Hosono N, Mukai Y, Ishii T, Yonenobu K, Yoshikawa H. Outcome of total en bloc spondylectomy for solitary metastasis of the thoracolumbar spine. J Spinal Disord Tech. 2004;17:297-300. https://doi.org/10.1097/ 01.bsd.0000096269.75373.9b.

3. Maranzano E, Bellavita R, Rossi R, De Angelis V, Frattegiani A, Bagnoli R, et al. Short-course versus split-course radiotherapy in metastatic spinal cord compression: results of a phase III, randomized, multicenter trial. J Clin Oncol. 2005;23:3358-65. https://doi.org/10.1200/JCO.2005.08.193.

4. Alongi F, Mazzola R, Ricchetti F. Consolidative local therapy in oligometastatic patients. Lancet Oncol. 2017;18(2): e60. https://doi.org/10.1016/ S1470-2045(17)30014-1

5. Ricardi U, Giaj Levra N, Badellino S, Alongi F. Role of consolidative stereotactic ablative radiotherapy in patients with oligometastatic non-small cell lung cancer. J Thorac Dis. 2017;9(8):2235-7. https://doi.org/10.21037/ jtd.2017.06.133.

6. Gomez, DR, Tang C, Zhang J, Blumenschein GR, Hernandez M, Lee JJ, Ye R, Palma DA, Louie AV, Camidge DR, Doebele RC, Skoulidis F, Gaspar LE, Welsh JW, Gibbons DL, Karam JA, Kavanagh BD, Tsao AS, Sepesi B, Swisher SG, Heymach JV. Local consolidative therapy vs. maintenance therapy or observation for patients with oligometastatic non-small-cell lung cancer: long-term results of a multi-institutional, phase II, randomized study. J Clin Oncol. 2019;37(18):1558-65. doi: https://doi.org/10.1200/JCO.19. 00201.

7. Alongi F, Fiorentino A, Gregucci F, Corradini S, Giaj-Levra N, Romano

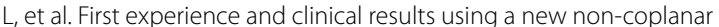
mono-isocenter technique (HyperArc ${ }^{\mathrm{TM}}$ ) for Linac-based VMAT radiosurgery in brain metastases. J Cancer Res Clin Oncol. 2019;145(1):193-200. https://doi.org/10.1007/s00432-018-2781-7.

8. Ricardi U, Filippi AR, Franco P. New concepts and insights into the role of radiation therapy in extracranial metastatic disease. Expert Rev Anticancer Ther. 2013;10:1145-55. https://doi.org/10.1586/14737140.2013. 846829.

9. Sahgal A, Bilsky M, Chang EL, Ma L, Yamada Y, Rhines LD, et al. Stereotactic body radiotherapy for spinal metastases: current status, with a 
focus on its application in the postoperative patient. J Neurosurg Spine. 2011;14(2):151-66. https://doi.org/10.3171/2010.9.SPINE091005.

10. De Bari B, Dahele M, Palmu M, Kaylor S, Schiappacasse L, Guckenberger M; ESTRO FALCON core. Short interactive workshops reduce variability in contouring treatment volumes for spine stereotactic body radiation therapy: Experience with the ESTRO FALCON programme and EduCase ${ }^{\text {TM }}$ training tool. Radiother Oncol. 2018 Apr;127(1):150-153. doi: https://doi. org/10.1016/j.radonc.2017.10.038. Epub 2017 Nov 20.

11. Cox BW, Spratt DE, Lovelock M, Bilsky MH, Lis E, Ryu S, Sheehan J, Gerszten PC, Chang E, Gibbs I, Soltys S, Sahgal A, Deasy J, Flickinger J, Quader M, Mindea S, Yamada Y. International Spine Radiosurgery Consortium consensus guidelines for target volume definition in spinal stereotactic radiosurgery. Int J Radiat Oncol Biol Phys. 2012;83(5):e597-605. https:// doi.org/10.1016/j.jijobp.2012.03.009 (Epub 2012 May 19 PMID: 22608954).

12. Giaj-Levra N, Niyazi M, Figlia V, Napoli G, Mazzola R, Nicosia L, Corradini S, Ruggieri R, Minniti G, Alongi F. Feasibility and preliminary clinical results of linac-based Stereotactic Body Radiotherapy for spinal metastases using a dedicated contouring and planning system. Radiat Oncol. 2019;14(1):184. https://doi.org/10.1186/s13014-019-1379-9.

13. Gregucci F, Fiorentino A, Corradini S, Figlia V, Mazzola R, Ricchetti F, et al. Linac-based radiosurgery or fractionated stereotactic radiotherapy with flattening filter-free volumetric modulated arc therapy in elderly patients: a mono-institutional experience on 110 brain metastases. Strahlenther Onkol. 2019;195(3):218-25. https://doi.org/10.1007/s00066-018-1405-0.

14. Ricardi U, Filippi AR, Guarneri A, Giglioli FR, Ciammella P, Franco P, et al. Stereotactic body radiation therapy for early stage non-small cell lung cancer: results of a prospective trial. Lung Cancer. 2010;68:72-7. https:// doi.org/10.1016/j.lungcan.2009.05.007.

15. Sprave T, Verma V, Förster R, Schlampp I, Bruckner T, Bostel T, et al. Randomized phase II trial evaluating pain response in patients with spinal metastases following stereotactic body radiotherapy versus threedimensional conformal radiotherapy. Radiother Oncol. 2018;128:274-82. https://doi.org/10.1016/j.radonc.2018.04.030.

16. Husain ZA, Sahgal A, De Salles A, Funaro M, Glover J, Hayashi M, et al. Stereotactic body radiotherapy for de novo spinal metastases: systematic review. J Neurosurg Spine. 2017;27(3):295-302. https://doi.org/10.3171/ 2017.1.SPINE16684.

17. Chiang A, Zeng L, Zhang L, Lochray F, Korol R, Loblaw A, et al. Pain flare is a common adverse event in steroid-naïve patients after spine stereotactic body radiation therapy: a prospective clinical trial. Int J Radiat Oncol Biol Phys. 2013;86(4):638-42. https://doi.org/10.1016/j.jijobp.2013.03.022.
18. Sahgal A, Myrehaug SD, Siva S, Masucci L, Foote MC, Brundage M, Butler J, Chow E et al. CCTG SC.24/TROG 17.06: a randomized phase II/III study comparing 24Gy in 2 stereotactic body radiotherapy (SBRT) Fractions Versus 20Gy in 5 Conventional Palliative Radiotherapy (CRT) Fractions for Patients with Painful Spinal Metastases. 2020 ASTRO's Annual Meeting.

19. Hearn N, Blazak J, Vivian P, Vignarajah D, Cahill K, Atwell D, Lagopoulos J, Min M. Prostate cancer GTV delineation with biparametric MRI and 68Ga-PSMA-PET: comparison of expert contours and semi-automated methods. Br J Radiol. 2021;94(1119):20201174. https://doi.org/10.1259/ bjr.20201174.

20. Meillan N, Bibault JE, Vautier J, Daveau-Bergerault C, Kreps S, Tournat H, Durdux C, Giraud P. Automatic Intracranial Segmentation: Is the Clinician Still Needed? Technol Cancer Res Treat. 2018;1 (17):1533034617748839. https://doi.org/10.1177/15330346177488839.

21. Francolini G, Desideri I, Stocchi G, Salvestrini V, Ciccone LP, Garlatti P, Loi M, Livi L. Artificial Intelligence in radiotherapy: state of the art and future directions. Med Oncol. 2020;37(6):50. https://doi.org/10.1007/ s12032-020-01374-w.

22. Men $\mathrm{K}$, Chen X, Zhang Y, Zhang T, Dai J, Yi J, Li Y. Deep deconvolutional neural network for target segmentation of nasopharyngeal cancer in planning computed tomography images. Front Oncol. 2017;20(7):315. https://doi.org/10.3389/fonc.2017.00315.

23. Zhong $Y$, Yang $Y$, Fang $Y$, Wang J, Hu W. A preliminary experience of implementing deep-learning based auto-segmentation in head and neck cancer: a study on real-world clinical cases. Front Oncol. 2021;5(11):638197. https://doi.org/10.3389/fonc.2021.638197.

24. Sharp G, Fritscher KD, Pekar V, Peroni M, Shusharina N, Veeraraghavan $H_{\text {, }}$ Yang J.Vision 20/20: perspectives on automated image segmentation for radiotherapy. Med Phys. 2014;41(5):050902. https://doi.org/10.1118/1. 4871620

25. Shi J, Ding X, Liu X, Li Y, Liang W, Wu J. Automatic clinical target volume delineation for cervical cancer in CT images using deep learning. Med Phys. 2021. https://doi.org/10.1002/mp.14898.

26. Feng $M$, Valdes $G$, Dixit N, Solberg TD. Machine learning in radiation oncology: opportunities, requirements, and needs. Front Oncol. 2018;17(8):110. https://doi.org/10.3389/fonc.2018.00110.

\section{Publisher's Note}

Springer Nature remains neutral with regard to jurisdictional claims in published maps and institutional affiliations.
Ready to submit your research? Choose BMC and benefit from:

- fast, convenient online submission

- thorough peer review by experienced researchers in your field

- rapid publication on acceptance

- support for research data, including large and complex data types

- gold Open Access which fosters wider collaboration and increased citations

- maximum visibility for your research: over $100 \mathrm{M}$ website views per year

At BMC, research is always in progress.

Learn more biomedcentral.com/submissions 